\title{
A novel family VIII carboxylesterase hydrolysing third- and fourth-generation cephalosporins
}

\author{
Jeong Ho Jeon ${ }^{1,3}$, Hyun Sook Lee ${ }^{1,2}$, Jung Hun Lee ${ }^{3}$, Bon-Sung Koo ${ }^{4}$, Chang-Muk Lee ${ }^{4}$, Sang Hee Lee ${ }^{3 *}$, \\ Sung Gyun Kang ${ }^{1,2^{*}}$ and Jung-Hyun Lee ${ }^{1,2^{*}}$
}

\begin{abstract}
A metagenomic library was constructed from a soil sample of spindle tree-rhizosphere. From this library, one clone with esterase activity was selected. The sequence analysis revealed an open reading frame (EstSTR1) encoded protein of 390 amino acids. EstSTR1 is a family VIII carboxylesterase and retains the S-X-X-K motif conserved in both family VIII carboxylesterases and class C $\beta$-lactamases. The estSTR1 gene was overexpressed in E. coli and the recombinant protein was purified by purified by metal chelating affinity chromatography and size-exclusion chromatography. EstSTR1 hydrolysed $p$-nitrophenyl esters, exhibited the highest activity toward p-nitrophenyl butyrate. Furthermore, EstSTR1 could hydrolyse third- and fourth-generation cephalosporins (cefotaxime and cefepime) as well as first-generation cephalosporin (cephalothin). Site-directed mutagenesis studies revealed that a catalytic residue, Ser71, of EstSTR1 plays an essential role in hydrolysing both antibiotics and $p$-nitrophenyl esters. We demonstrate that a metagenomederived carboxylesterase displays $\beta$-lactam-hydrolysing activities toward third-and fourth-generation cephalosporins.
\end{abstract}

Keywords: Metagenome, $\beta$-Lactamase, Carboxylesterase, Extended-spectrum cephalosporins

\section{Background}

Carboxylesterases (EC3.1.1.1) hydrolyse emulsified esters of short-chain carboxylic acids, retaining a characteristic $\alpha / \beta$ hydrolase fold with the G-X-S-X-G motif in the active site which contains a conserved serine residue (Bornscheuer 2002; Nardini and Dijkstra 1999). Based on conserved sequence motifs and biological properties, microbial carboxylesterases have been classified into eight families (Arpigny and Jaeger 1999). Particularly, the primary sequences of family VIII carboxylesterases with a conserved S-X-X-K motif instead of the G-X-S$\mathrm{X}-\mathrm{G}$ motif of canonical carboxylesterases are similar to those of class C $\beta$-lactamases (Arpigny and Jaeger 1999).

\footnotetext{
*Correspondence: sangheelee@mju.ac.kr; sgkang@kiost.ac; jlee@kordi.re.k

${ }^{1}$ Marine Biotechnology Research Division, Korea Institute of Ocean Science and Technology, Ansan 15627, Republic of Korea

${ }^{3}$ National Leading Research Laboratory of Drug Resistance Proteomics, Department of Biological Sciences, Myongji University, 116 Myongjiro, Yongin, Gyeonggido 17058, Republic of Korea

Full list of author information is available at the end of the article
}

A previous report (Wagner et al. 2002) revealed that the overall structure of EstB from Burkholderia gladioli, composed of a mixed $\alpha / \beta$ domain and a small helical domain, was similar to that of class $C \beta$-lactamases.

Functional metagenomic screening, in which shotguncloned DNA fragments are selected for survival to antibiotic exposure, have been increasingly applied to the characterisation of many antibiotic resistance reservoirs. In recent study, a new class A $\beta$-lactamase derived from a polluted river metagenome library has been identified by functional screening (Vercammen et al. 2013). These experiments have demonstrated that antibiotic resistance genes are highly diverse and widely distributed, frequently bearing little to no similarity to known sequences (Pehrsson et al. 2013). The relationship between serine$\beta$-lactamases and family VIII carboxylesterases has been surprisingly evidenced by the metagenomic approach of screening ester-hydrolysing activities that perform unrelated functions to previously identified resistance genes. New family VIII carboxylesterases that originated from metagenomic libraries of various environmental 
samples (Elend et al. 2006; Rashamuse et al. 2009; Kim et al. 2010; Jeon et al. 2011; Yu et al. 2011; Mokoena et al. 2013), including EstC (Rashamuse et al. 2009), EstMN1 (Yu et al. 2011), EstM-N2 (Yu et al. 2011), and Est22 (Mokoena et al. 2013), exhibited hydrolysing activity for nitrocefin, but did not display $\beta$-lactamase activity for $\beta$-lactam antibiotics. Recently, the family VIII carboxylesterase, EstU1, which was selected from a soil metagenomic library by screening for esterase activity showed a bona fide hydrolysing activity toward both the ester bond of $p$-nitrophenyl esters and the amide bond of $\beta$-lactams, apparently utilising the same active site residues for both reactions, as supported by site-directed mutagenesis, confirming the functional relationship between family VIII carboxylesterases and $\beta$-lactamases (Jeon et al. 2011).

In this study, we report a novel family VIII carboxylesterase identified from a soil metagenomic library. EstSTR1 display an esterase activity for $p$-nitrophenyl esters. In particular, EstSTR1 exhibits a broad range of $\beta$-lactam hydrolytic activities for first-generation cephalosporin (cephalothin), third-generation cephalosporin (cefotaxime), and fourth-generation cephalosporin (cefepime). Here, we demonstrate the functional characterisation of EstSTR1, as well as site-directed mutagenesis and its structural discussion to understand the mechanism of EstSTR1.

\section{Methods}

Strains, metagenomics library construction, and screening lipolytic activity

E. coli DH5 $\alpha$ and BL21(DE3) were used for all cloning and expression experiments, respectively. A soil sample $\left(35^{\circ} 52^{\prime} \mathrm{N}, 127^{\circ} 3^{\prime} \mathrm{E}\right)$ was collected from the Korea Expressway Corporation Arboretum in Jeonju City, South Korea. Soil DNA was prepared by directed DNA extraction and purification as previously described (Kim et al. 2007). The metagenomic cosmid library was constructed according to the method of Yun et al. (2005). Two-step DNA purification was applied to remove humic compounds present in the soil DNAs using pulsed-field gel electrophoresis (PFGE) (CHEF, BioRad). To remove humic compounds in DNA extracted from soil sample, $1 \%$ low melting point agarose was prepared and crude DNA was fractionated by PFGE under a $4 \mathrm{~V} \mathrm{~cm}^{-1}$ electrical field at $14{ }^{\circ} \mathrm{C}$ for $12 \mathrm{~h}$. A gel containing 100-190 kb of DNA was purified by agarase ( $1 \mathrm{U}$ per $100 \mathrm{mg}$ slice, Takara, Japan). The isolated DNA was partially digested by Sau3AI $\left(0.05 \mathrm{U} \mathrm{\mu l}^{-1}\right.$ of DNA, $37^{\circ} \mathrm{C}$ for $1 \mathrm{~h}$ ), and then the digested DNA was fractionated by PFGE. A gen containing approximately $40-\mathrm{kb}$ lengths DNA was again purified by agarase. The 40-kb DNA was ligated into a pSuperCosI (Stratagene, La Jolla, CA) and packaged using MaxPlax Lambda
Packaging Extracts (Epicentre, Madison, WI). For screening esterase activity, the transformants were plated on Luria-Bertani (LB) agar plates with chloramphenicol $\left(12.5 \mu \mathrm{g} \mathrm{ml}^{-1}\right)$ and tributyrin $(1 \%)$. After incubation at $37^{\circ} \mathrm{C}$ for 1 day, the plates were subsequently incubated at $4{ }^{\circ} \mathrm{C}$ for a week. Candidate colonies were selected based on the presence of clear zone on the plate.

\section{Subcloning and sequence analysis}

Positive colony (pCosSTR1) with a clear halo was selected on the plate. To identify the gene encoding esterase active, the subclone library was constructed by method as described by Jeon et al. (2011). The transformants with esterase activity were selected by the presence of the clear halo zone on LB agar plates containing $100 \mu \mathrm{g} \mathrm{ml}^{-1}$ ampicillin and $1 \%$ tributyrin. DNA sequencing of the subclone with esterase activity was performed with an ABI3100 (PE Applied Biosystems, Foster City, CA, USA) and assembled using the Vector NTI suite 7 software package (InforMax, North Bethesda, MD, USA). The open reading frames (ORFs) and sequence homology searches in the complete assembled sequence were analysed by the ORF finder and BlastX search provided by the National Center for Biotechnology Information (NCBI) (Altschul et al. 1997).

\section{Multiple alignment and phylogenetic analysis}

Multiple sequence alignments were carried out by the ClustalW program (Thompson et al. 1994) for the protein sequences. To compare the amino acid sequences of EstSTR1 and EstU1, we performed sequence alignment using the Expresso program on the T-Coffee Server (Notredame et al. 2000), found at the ExPASy web site (http://tcoffee.vital-it.ch/apps/tcoffee/index.html). Expresso is able to combine sequence information with protein structural information. Molecular Evolutionary Genetics Analysis 4.1 software (MEGA, version 4.1) (Tamura et al. 2007) was used to make the phylogenetic tree using a neighbour-joining method (Saitou and Nei 1987).

\section{Expression and purification of recombinant EstSTR1}

The estSTR1 gene was amplified by PCR the following primers: STR1-F (5'-GAGACCCCATATGAGCACCGG GATCGAAATTCAAG-3') and STR1-R (5'-CTATCTC GAGGCTGTTCGGCAGGCAGCGATAC-3'). NdeI and XhoI sites for cloning are underlined. The PCR product (1173 bp) for the estSTR1 gene was cloned into pET-24a $(+)$ vector containing the T7 polymerase promoter system (Novagen, Madison, Wisconsin, USA), and then the recombinant plasmid was introduced into E. coli BL21(DE3) cells. When E. coli BL21(DE3) cell harbouring pET-24a $(+) / \mathrm{His}_{6}$-EstSTR1 reached 
approximately 0.6 at $600 \mathrm{~nm}, 1 \mathrm{mM}$ IPTG (isopropyl $\beta$-D-1-thiogalactopyranoside) was added to induce expression. The cells were harvested by centrifugation $\left(5000 \times g, 4{ }^{\circ} \mathrm{C}, 20 \mathrm{~min}\right)$ after induction at $25{ }^{\circ} \mathrm{C}$ for $10 \mathrm{~h}$, resuspended in $10 \mathrm{~mL}$ of buffer A ( $50 \mathrm{mM}$ Tris- $\mathrm{HCl} \mathrm{pH}$ 8.0, $10 \%$ glycerol, $100 \mathrm{mM} \mathrm{KCl}$ ). The solution was vortexed, and then sonicated for $20 \mathrm{~min}$. To obtain the soluble protein, the crude lysate disrupted by sonication was centrifuged $\left(15,000 \times g, 4{ }^{\circ} \mathrm{C}, 60 \mathrm{~min}\right)$. To purify EstSTR1 with the $\mathrm{His}_{6}$ tag, the soluble proteins were loaded onto a column of TALON ${ }^{\circledR}$ metal affinity resin (BD Biosciences Clontech, Palo Alto, CA, USA) and washed with buffer B (50 mM Tris- $\mathrm{HCl}$ pH 8.0, $10 \mathrm{mM}$ imidazole, $10 \%$ glycerol, $100 \mathrm{mM} \mathrm{KCl})$. The bound EstSTR1 was eluted with buffer C (50 mM Tris- $\mathrm{HCl}$ pH 8.0, $300 \mathrm{mM}$ imidazole, $10 \%$ glycerol, $100 \mathrm{mM} \mathrm{KCl}$ ). For further purification, size exclusion chromatography was performed. Eluted sample was purified using Superdex-75 (16/60) column (GE Healthcare, Piscataway, NJ, USA) equilibrated and run using buffer $\mathrm{D}(150 \mathrm{mM} \mathrm{NaCl}, 20 \mathrm{mM}$ Tris- $\mathrm{HCl} \mathrm{pH}, 7.8)$.

\section{Characterizations of EstSTR1 for pNP esters}

Enzyme activity was determined by colorimetric method measuring released $p$-nitrophenol from $p$-nitrophenyl $(p N P)$ esters (Sigma, St. Louis, MO, USA) at $405 \mathrm{~nm}$. Esterase activity was measured by reaction mixture with $1 \mathrm{mM} p$-nitrophenyl esters in $50 \mathrm{mM}$ Tris- $\mathrm{HCl}(\mathrm{pH}$ 8.0) containing $1 \%(\mathrm{v} / \mathrm{v})$ acetonitrile at $35{ }^{\circ} \mathrm{C}$. The substrate specificity of enzyme was determined in the presence of $1 \mathrm{mM}$ of $p$-nitrophenyl esters with different aliphatic side chains: acetate $(\mathrm{C} 2)$, butyrate $(\mathrm{C} 4)$, hexanoate (C6), octanoate (C8), decanoate (C10), laurate (C12), myristate (C14), palmitate (C16), and stearate (C18). The optimum temperature of enzyme was determined at temperatures ranging from 5 to $70{ }^{\circ} \mathrm{C}$ using $p$-nitrophenyl butyrate as a substrate in $50 \mathrm{mM}$ Tris-HCl buffer (pH 8.0). For optimization of the $\mathrm{pH}$ of enzyme, enzyme activity was measured for a $\mathrm{pH}$ range of 4.0-10.0. The buffers used were $50 \mathrm{mM}$ sodium acetate $(\mathrm{pH} 4.0-6.0), 50 \mathrm{mM}$ sodium phosphate (pH 6.0-7.5), $50 \mathrm{mM}$ Tris- $\mathrm{HCl}$ ( $\mathrm{pH} 7.5-8.5)$, and $50 \mathrm{mM} \mathrm{CHES} \mathrm{(pH} \mathrm{8.5-10.0).}$

\section{$\beta$-Lactamase assay of EstSTR1}

Antibiotics (cephalothin, cefoxitin, cefotaxime, and cefepime) were obtained from Sigma-Aldrich (St. Louis, MO, USA). The chemical structures of cephalosporins (cephalothin, cefoxitin, cefotaxime, and cefepime) are shown in the Additional file 1: Figure S1. The hydrolysing activity of EstSTR1 for cephalosporins was measured by the paper disc method as previously described (Jeon et al. 2011). The enzyme $(330 \mu \mathrm{M})$ was incubated with antibiotic substrates ( $3 \mathrm{mM}$ cephalothin, $1 \mathrm{mM}$ cefoxitin,
$1 \mathrm{mM}$ cefotaxime, and $1 \mathrm{mM}$ cefepime) in $50 \mathrm{mM}$ Tris$\mathrm{HCl}(\mathrm{pH} 8.0)$ for $2 \mathrm{~h}$ at $35^{\circ} \mathrm{C}$, and then reaction mixtures were loaded onto small paper discs. After $8 \mathrm{~h}$ incubation at $37{ }^{\circ} \mathrm{C}$, the diameters of the inhibition zones around the small paper discs were recorded. For comparison of $\beta$-lactam hydrolysing activity, a negative control containing antibiotics without enzyme and a positive control containing antibiotics and the CMY-10, a plasmid-encoded class $\mathrm{C}$ extended-spectrum $\beta$-lactamase (ESBL) from Enterobacter aerogenes (Kim et al. 2006), were used.

\section{Determination of kinetic parameters}

The kinetic parameters $\left(\mathrm{k}_{\mathrm{cat}}\right.$ and $\left.\mathrm{K}_{\mathrm{m}}\right)$ of EstSRT1 were obtained by measuring the absorbance variation using the molecular extinction coefficient of each substrate: $p$-nitrophenyl butyrate $\left(\Delta \varepsilon_{405}=13,500 \mathrm{M}^{-1} \mathrm{~cm}^{-1}\right)$, cephalothin $\left(\Delta \varepsilon_{262}=-7660 \quad \mathrm{M}^{-1} \mathrm{~cm}^{-1}\right)$, cefotaxime $\left(\Delta \varepsilon_{264}=-7250 \mathrm{M}^{-1} \mathrm{~cm}^{-1}\right)$, and cefepime $\left(\Delta \varepsilon_{267}=-9120 \mathrm{M}^{-1} \mathrm{~cm}^{-1}\right)$. The assay for $p$-nitrophenyl butyrate was conducted in $50 \mathrm{mM}$ CHES (pH 9.0) containing (approximately $2.43 \mathrm{nM}$ ) and substrates $(10-600 \mu \mathrm{M})$. The assays for $\beta$-lactam substrates were conducted in $10 \mathrm{mM}$ MES buffers (pH 6.8) with enzymes $(396 \mu \mathrm{M})$, substrates $(10-500 \mu \mathrm{M})$, and bovine serum albumin $\left(20 \mu \mathrm{g} \mathrm{ml}^{-1}\right)$. Steady-state kinetic constants were determined by fitting the initial rates (in triplicate) directly to the Henri-Michaelis-Menten equation using non-linear regression with the program DYNAFIT (Kuzmic 1996). When $K_{m}$ values for $\beta$-lactam substrates were too low to be determined, the values were determined as competitive inhibition constants, $K_{i}$, in the presence of a reporter substrate $(100 \mu \mathrm{M}$ cephalothin), and $K_{\mathrm{i}}$ values were calculated as previously described (Galleni and Frere 1988; De Meester et al. 1987).

\section{Site-directed mutagenesis of EstSTR1}

A site-directed change to alanine (S71A) was made using the Stratagene Quik Change kit (La Jolla, CA, USA). The primers (S71A-F and S71A-R) designed to introduce the S71A substitution were as follows: S71A-F (5'-CGCT CATCAATACCTATGCGACCACCAAGGGCATGG-3') and S71A-R (5'-CCATGCCCTTGGTGGTCGCATAGG TATTGATGAGCG-3'). The sequence corresponding to the mutated codons are underlined. The catalytic activity of the variant was tested and compared with that of the wild-type enzyme.

\section{Nucleotide sequence accession number}

The nucleotide sequence of EstSTR1 has been deposited in the GenBank database under the accession number KJ530984. 


\section{Results}

Metagenomic library screening and sequence analysis A cosmid metagenomic library consisting of 7968 clones was constructed using high molecular weight DNA extracted from a soil sample of spindle treerhizosphere, taken near the Korea Expressway Corporation Arboretum in South Korea. The insert sizes for the cosmid clones ranged from 35 to $40 \mathrm{~kb}$, with nonredundant patterns. The entire library was screened for lipolytic activity on $1 \%$ tributyrin plates. One cosmid clone (36 kb insert size) forming a clear halo zone on the plate was selected for further analysis. To characterise the gene exhibiting esterase activity, the subcloning experiment with a pUC118/HincII/BAP plasmid was performed and subclone (pUCSTR1) with a short insert of $1825 \mathrm{bp}$ was found. The sequence analysis of the pUCSTR1 insert DNA showed the presence of one open reading frame (ORF) of 1173 bp (estSTR1), encoding a polypeptide of 390 amino acids. Primary sequence analysis of EstSTR1 indicated that it was similar to a putative esterase (WP_007223494) from Marine gamma proteobacterium HTCC2143 (47 \% identity), class C $\beta$-lactamase (WP_004621811) from Caulobacter vibrioides (47\% identity), and $\beta$-lactamase (WP_005321278) from Streptomyces pristinaespiralis (46 \% identity). Multiple sequence alignment of EstSTR1 and its homologs showed that the S-X-X-K motif is well conserved in family VIII carboxylesterases (Jeon et al. 2011; Kim et al. 2010; Rashamuse et al. 2009; Elend et al. 2006), class $C$ $\beta$-lactamases (Knox et al. 1996), and penicillin-binding proteins (PBPs) (Joris et al. 1988) (Fig. 1). Based on the esterase/lipase classification system (families I-VIII) proposed by Arpigny and Jaeger (1999), the phylogenetic relationship was analysed. The phylogenetic analysis showed that EstSTR1 was grouped with family VIII carboxylesterases (Fig. 2).

\section{Purification and characterisation of EstSTR 1}

To invest the biochemical properties of EstSTR1, the estSTR1 gene ligated into $\mathrm{pET}-24 \mathrm{a}(+)$ was overexpressed in E. coli. SDS-PAGE analysis of purified EstSTR1 showed a single protein band which correlated well with the theoretical mass $(42 \mathrm{kDa})$ of EstSTR1 (Additional file 1: Figure S2). The hydrolytic activity of purified recombinant EstSTR1 for $p$-nitrophenyl esters (C2-C18) was investigated. EstSTR1 showed substrate preference for a wide range of substrates (C2 to $\mathrm{C} 10)$, and $p$-nitrophenyl butyrate (C4) was most rapidly hydrolysed (Fig. 3). However, no enzyme activity was detected for $p$-nitrophenyl esters (C12-C18) with a longer chain (Fig. 3). The optimum activity of EstSTR1 was measured at a temperature range of $5-70{ }^{\circ} \mathrm{C}$ and $\mathrm{pH}$ range of 6.0 and 10.0. The enzyme showed a temperature optimum at $40{ }^{\circ} \mathrm{C}$ (Additional file 1: Figure S3A). The optimum activity occurred at an alkaline $\mathrm{pH}$ in the range of $\mathrm{pH} 9-10$, threefold higher than the activity at $\mathrm{pH}$ 8.0, indicating that EstSTR1 is an alkaline esterase (Additional file 1: Figure S3B).

\section{Determination of $\beta$-lactamase activity}

Previously, we reported that a metagenome derived esterase, a family VIII carboxylesterase (EstU1) could hydrolyse first-generation cephalosporins (cephaloridine, cephalothin, and cefazolin) (Jeon et al. 2011). The crystal structure of cephalothin complex of EstU1 revealed an acyl-enzyme intermediate in which Ser100 (the nucleophile) in first motif of EstU1 is covalently linked to the carbonyl carbon of the hydrolysed $\beta$-lactam ring of cephalothin (Cha et al. 2013). Though the amino acid sequence of EstSTR1 showed low similarity to EstU1 from uncultured bacterium (15\% identity), three active site residues (S100, K103, and Y218) essential for the $\beta$-lactam hydrolytic activity in EstU1 could be found in EstSTR1 (Fig. 1).

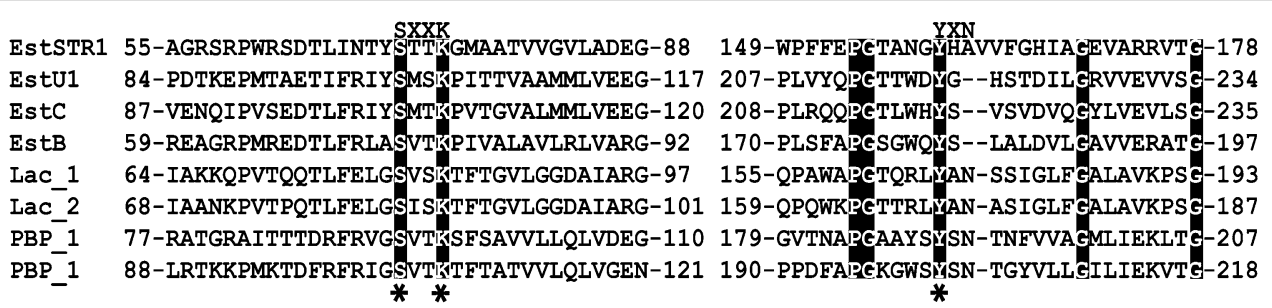

Fig. 1 Conserved sequence blocks from a multiple sequence alignment of EstSTR1 and related family VIII carboxylesterases, class C $\beta$-lactamases, and penicillin-binding proteins (PBPs). Family VIII carboxylesterases are represented by EstU1 (uncultured bacterium, JF791800), EstC (uncultured bacterium, ACH88047), and EstB (Burkholderia gladioli, AAF59826). Class C $\beta$-lactamases are represented by Lac-1 (Escherichia coli, AAA23441) and Lac-2 (Enterobacter cloacae, P05364) and penicillin-binding proteins are represented by PBP-1 (Streptomyces sp. R61, P15555) and PBP-2 (Bacillus cereus, CAA09676). Asterisks indicate conserved active site residues. Identical residues are shown as white letters on a dark background 


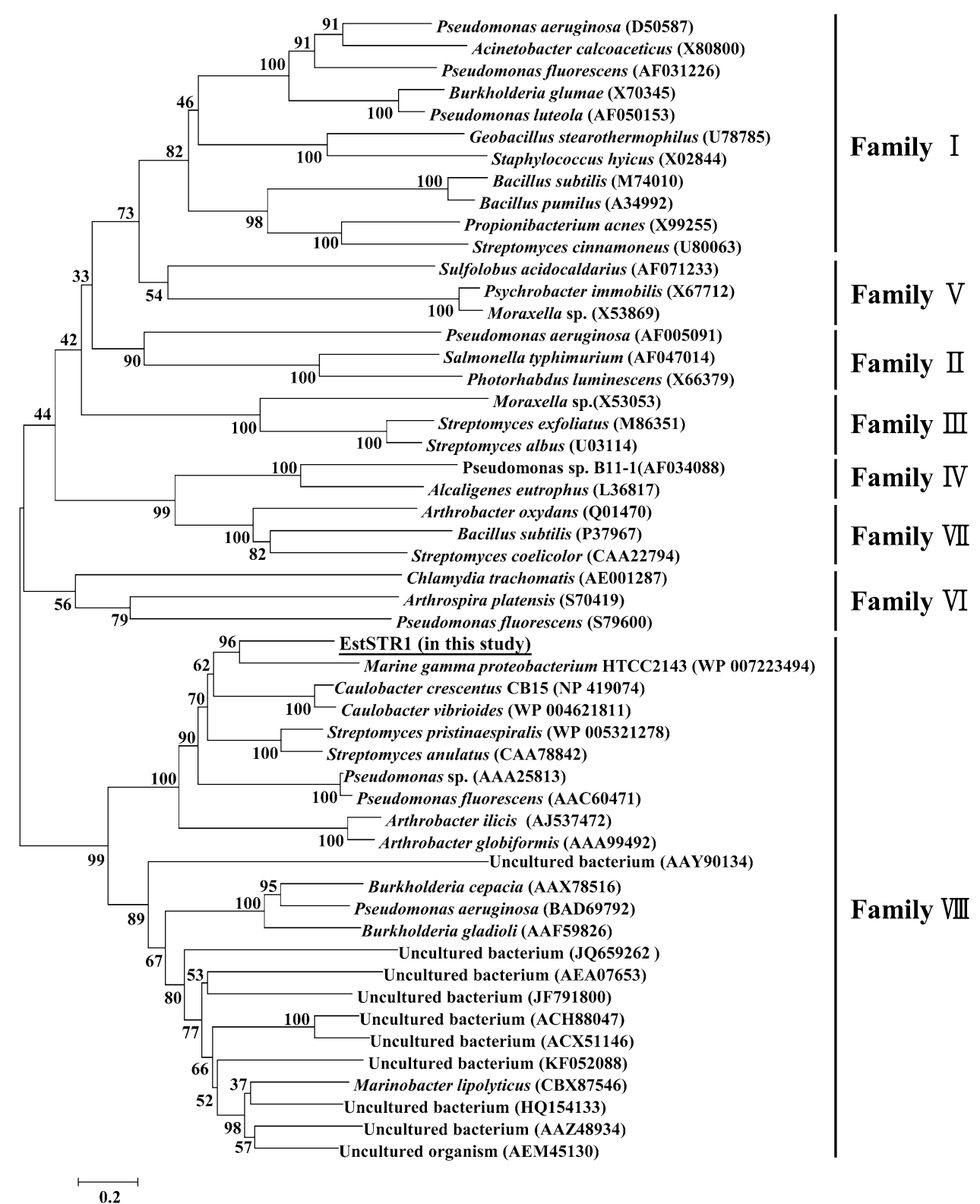

Fig. 2 Phylogenetic relationship of EstSTR1 with the lipolytic enzymes including family VIII carboxylesterases. The tree was constructed using the MEGA 4.1 program with the neighbor-joining algorithm. Only bootstrap values higher than $50 \%$ are shown. Bar 0.2 substitutions per amino acid site

For these reasons, we examined whether EstSTR1 could hydrolyse various $\beta$-lactam antibiotics, cephalothin (firstgeneration cephalosporins), cefoxitin (second-generation cephalosporin), cefotaxime (third-generation cephalosporins), and cefepime (fourth-generation cephalosporin). Compared with that of the negative control, the diameters of the inhibition zones around the discs containing cephalothin, cefotaxime, and cefepime incubated with EstSTR1 were decreased from 27 to $22 \mathrm{~mm}$ in cefotaxime and from 26 to $23 \mathrm{~mm}$ in cefepime (Fig. 4). The result implies that the antibiotic efficacies of cephalothin, cefotaxime, and cefepime are affected by EstSTR1 activity. However, EstSTR1 did not appear to change the antibiotic efficacy of cefoxitin because the size alteration of the clear zone around paper disc did not show compared with that of the negative control. Thus, EstSTR1 displays $\beta$-lactam hydrolytic activity for cephalothin, cefotaxime, and cefepime except for cefoxitin. 


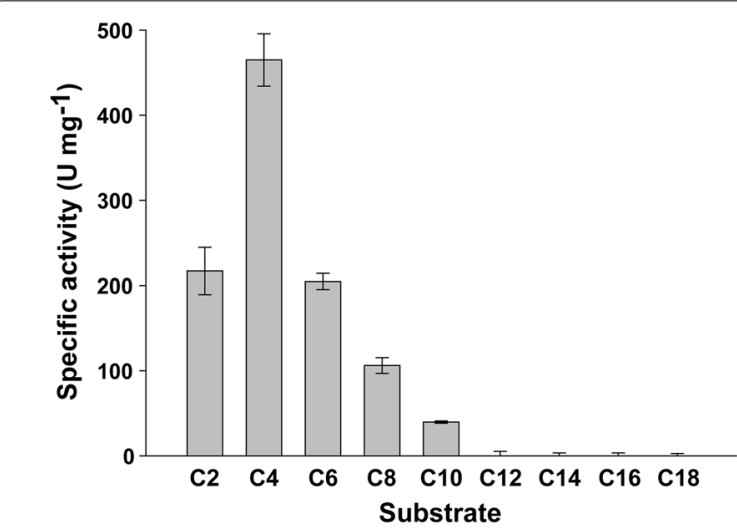

Fig. 3 Substrate preference of the purified EstSTR1 toward $p$-nitrophenyl esters. Nine $p$-nitrophenyl esters: C2 p-nitrophenyl acetate, C4 $p$-nitrophenyl butyrate, C6 p-nitrophenyl hexanoate, C8 p-nitrophenyl octanoate, C10 p-nitrophenyl decanoate, C12 p-nitrophenyl laurate, C14 p-nitrophenyl myristate, C16 p-nitrophenyl palmitate, C18 $p$-nitrophenyl stearate. Error bars indicate standard deviations $(n=3)$

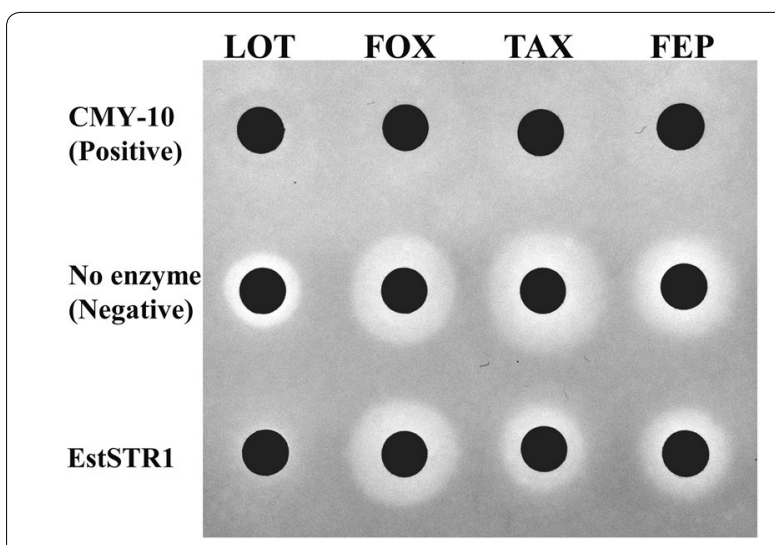

Fig. 4 Disc diffusion assay for confirming the hydrolysis of antibiotics by EstSTR1. This assay was performed by incubating purified EstSTR1 with antibiotics, including $3 \mathrm{mM}$ cephalothin, $1 \mathrm{mM}$ cefoxitin, $1 \mathrm{mM}$ cefotaxime, and $1 \mathrm{mM}$ cefepime in $50 \mathrm{mM}$ Tris- $\mathrm{HCl}$ (pH 8.0) for $2 \mathrm{~h}$ at $35^{\circ} \mathrm{C}$. The reaction mixtures were adsorbed onto a paper disk and placed on agar seeded with E. coli BL21(DE3). The diameters of the inhibition zones around the discs appeared after an $8 \mathrm{~h}$ at $37^{\circ} \mathrm{C}$. The negative controls were samples containing antibiotics only and the positive controls were reaction mixtures containing CMY-10 and antibiotics. Antibiotics: LOT cephalothin, FOX cefoxitin, TAX cefotaxime, FEP cefepime

\section{Determination of kinetic parameters}

The kinetic parameters of EstSTR1 for cephalosporins (cephalothin, cefotaxime, and cefepime) and $p$-nitrophenyl butyrate were investigated. The $\mathrm{K}_{\mathrm{m}}$ and $\mathrm{k}_{\mathrm{cat}}$ values for $p$-nitrophenyl butyrate were approximately 10 - and 20-fold higher than those of EstU1 (6.03 $\mu \mathrm{M}$ and $15.72 \mathrm{~s}^{-1}$ ) (Jeon et al. 2011), respectively (Table 1). Kinetic analysis of EstSTR1 revealed that this enzyme has a hydrolysing activity for cephalothin, cefotaxime, and cefepime (Table 1). The catalytic efficiencies of EstSRT1 for cephalothin, cefotaxime, and cefepime were similar to that of EstU1 for cefazolin $\left(3.035 \mathrm{M}^{-1} \mathrm{~s}^{-1}\right.$ ) (Jeon et al. 2011) (Table 1). Although catalytic efficiencies of EstSTR1 for $\beta$-lactams were very low level, catalytic efficiency of $\beta$-lactamase I $\left(4 \mathrm{M}^{-1} \mathrm{~s}^{-1}\right)$ from Bacillus cereus for a $\beta$-lactam (Martin Villacorta et al. 1991) is similar to the level of the EstSTR1.

\section{Site-directed mutagenesis}

Because EstSTR1 retains the catalytic (or nucleophilic) serine (Ser71) correlated with the Ser100 of EstU1, we wondered whether a single nucleophile (Ser71) was involved or whether the enzyme harbored two active sites. We performed site-directed mutagenesis to confirm the effect of substitution of a single serine on both activities of EstSTR1. The nucleophilic serine (Ser71) in EstSTR1 was mutated into an alanine residue (Ala71) and the mutant protein (S71A) was purified and characterised, compared with the wild-type EstSTR1. The mutant protein (S71A) was inactive for cephalosporins and $p$-nitrophenyl butyrate (Table 1 ). This result suggests that the serine residue is essential for both activities.

\section{Discussion}

In this study, a novel family VIII carboxylesterase, designated as EstSTR1, was identified by active screening of a metagenomic library constructed from a soil sample of tree-rhizosphere collected near in the Korea Expressway Corporation Arboretum in South Korea. EstU1 and EstSTR1 were found within two soil functional metagenomes of really a few clones $(<10,000)$, which means that the retrieved genes are likely to be highly prevalent in soil. The amino acid sequence of EstSTR1 showed that the $\mathrm{S}-\mathrm{X}-\mathrm{X}-\mathrm{K}$ motif encompassing the nucleophilic serine residue of serine- $\beta$-lactamases was conserved and EstSTR1 was grouped together with the family VIII carboxylesterases. The $\beta$-lactam hydrolytic activities of EstSTR1 for first-generation cephalosporin (cephalothin), third-generation cephalosporin (cefotaxime), and fourthgeneration cephalosporin (cefepime) were clearly demonstrated by the disc diffusion assay and kinetics as well.

A previous report (Cha et al. 2013) revealed that the structure of EstU1 had a $\beta$-lactamase-like modular architecture and that the active site residues (Ser100, Lys103, and Tyr218) of EstU1 played an important role in hydrolysing both ester and amide bonds (Cha et al. 2013; Jeon et al. 2011). The corresponding active site residues, Ser71, Lys74, and Tyr160, could be predicted in EstSTR1 and site-directed mutagenesis of the EstSTR1 serine residue demonstrated that this residue was crucial for both the esterase and $\beta$-lactamase activities. In addition, the active 
Table 1 Kinetic parameters for hydrolysis of p-nitrophenyl butyrate and cephalosporins (cephalothin, cefotaxime, and cefepime) by EstSTR1 and its mutant enzyme (S71A)

\begin{tabular}{|c|c|c|c|c|c|c|}
\hline \multirow[t]{2}{*}{ Substrates } & \multicolumn{2}{|l|}{$k_{\text {cat }}\left(s^{-1}\right)$} & \multicolumn{2}{|l|}{$\mathrm{K}_{\mathrm{m}}(\mu \mathrm{M})$} & \multicolumn{2}{|l|}{$\mathrm{k}_{\mathrm{cat}} / \mathrm{K}_{\mathrm{m}}\left(\mathrm{M}^{-1} \mathrm{~s}^{-1}\right)$} \\
\hline & Wild & S71A & Wild & S71A & Wild & S71A \\
\hline p-nitrophenyl butyrate & $297.12 \pm 5.90$ & $\mathrm{nh}$ & $65.62 \pm 5.92$ & $\mathrm{nh}$ & $4.52 \pm 0.001 \times 10^{6}$ & $\mathrm{nh}$ \\
\hline Cephalothin & $4.63 \pm 0.03 \times 10^{-5}$ & $\mathrm{nh}$ & $16.58 \pm 0.18$ & $\mathrm{nh}$ & $2.78 \pm 0.03$ & $\mathrm{nh}$ \\
\hline Cefotaxime & $1.57 \pm 0.04 \times 10^{-6}$ & $\mathrm{nh}$ & $0.90 \pm 0.004^{\mathrm{a}}$ & $\mathrm{nh}$ & $1.67 \pm 0.01$ & $\mathrm{nh}$ \\
\hline Cefepime & $1.63 \pm 0.03 \times 10^{-6}$ & $\mathrm{nh}$ & $0.19 \pm 0.003^{\mathrm{a}}$ & $\mathrm{nh}$ & $8.48 \pm 0.01$ & $\mathrm{nh}$ \\
\hline
\end{tabular}

nh not hydrolysed

a Determined $K_{\mathrm{i}}$ values

site in EstU1 was divided into R1 and R2 subsites. The R1 subsite is defined by the $\mathrm{R} 1$ segment, the $\beta 8-\beta 9$ turn, and the $\Omega$-loop. The R2 subsite is surrounded by the R2' segment, the R2 segment, and $\beta 8$, with the nucleophilic serine. The R1 subsite accommodates the R1 side-chain of cephalosporins and the $\mathrm{R} 2$ subsite represents the opposite region interacting with the R2 side-chain of cephalosporins (Kim et al. 2006). EstU1 only hydrolysed first-generation cephalosporins (e.g., cephalothin, cephaloridine, and cefazolin); however, EstSTR1 hydrolysed third- and fourth-generation cephalosporins as well as first-generation cephalosporin. Cefotaxime and cefepime have the R1 side chain larger than that of cephalothin (Additional file 1: Figure S1). This result implies that the R1 subsite of EstSTR1 may be wider than that of EstU1. We confirmed variations in the $\Omega$-loop and R1 segment in the R1 subsite via sequence alignment of EstSTR1 and EstU1 (Additional file 1: Figure S4). Therefore, these results suggest that variation of the R1 subsite in EstSTR1 allows the active site of EstSTR1 to access substrates (cefotaxime and cefepime), resulting in the efficient acylation.

The kinetic study of EstSTR1 also indicated that EstSTR1 showed weak $\beta$-lactamase activity for the antibiotic substrates, cephalothin, cefotaxime, and cefepime. A hydrolase mechanism for antibiotics has recently been demonstrated from the crystal structure of cephalothin complex of EstU1. A two-strep hydrolysis process composed of acylation and deacylation steps, mediated by the nucleophilic serine has been proposed in family VIII carboxylesterases and serine- $\beta$-lactamases. The weak hydrolytic activity of EstU1 for $\beta$-lactam antibiotics likely indicates that the active site of EstU1 cannot show the efficient deacylation reaction. The EstSTR1 deacylation efficiency on $\beta$-lactam antibiotics may therefore be lower than that of typical extended-spectrum $\beta$-lactamase, lowering the overall hydrolysis efficiency.

\section{Conclusion}

One gene screened from a soil metagenomic library was identified as having an S-X-X-S motif found in family VIII carboxylesterases and serine- $\beta$-lactamases. The purified EstSTR1 protein showed hydrolysing activity for $p$-nitrophenyl esters and antibiotic substrates such as cephalothin, cefotaxime, and cefepime. Similar to EstU1, EstSTR1 contains only the active site residues (Ser100, Lys103, and Tyr218) responsible for the hydrolysing activity toward both $\beta$-lactam antibiotics and $p$-nitrophenyl esters. EstSTR1 is the first esterase that hydrolyses third-generation cephalosporin (cefotaxime) and fourthgeneration cephalosporin (cefepime). To elucidate the detailed catalytic mechanism of EstSTR1, further studies will be required, including the crystallographic determination of EstSTR1's structure.

\section{Additional file}

Additional file 1: Figure S1. Chemical structures of cephalothin (A) cefoxitin (B), cefotaxime (C), and cefepime (D). The R1 and R2 side-chains located at $\mathrm{C} 7$ and $\mathrm{C} 3$ position of the $\beta$-lactam nucleus are labeled; Figure S2. SDS-PAGE of the purified EstSTR1 protein.M, Molecular size markers; T, whole-cell extracts; S, soluble fraction; I, insoluble fraction; P1, EstU1 purified by Ni-NTA column; P2, EstU1 purified by Superdex 75 gel filtration column. The purified EstSTR1 corresponded to a molecular mass of approximately $42 \mathrm{kDa}$ and is indicated by arrow; Figure S3. Effects of temperature $(\mathrm{A})$ and $\mathrm{pH}(\mathrm{B})$ on the activity of EstSTR1. Enzyme activity was measured using $p$-nitrophenyl butyrate as a substrate at various temperatures. The buffers used were $50 \mathrm{mM}$ sodium acetate buffer (closed circles; $\mathrm{pH} 4.0$ to 6.0), $50 \mathrm{mM}$ sodium phosphate buffer (open circles; pH 6.0 to 7.5), $50 \mathrm{mM}$ Tris- $\mathrm{HCl}$ buffer (closed triangles; $\mathrm{pH} 7.5$ to 8.5), and 50 $\mathrm{mM}$ CHES buffer (open triangles; $\mathrm{pH} 8.5$ to 10.0). The highest value of each enzyme activity was set at 100\%; Figure S4. Sequence alignment of EstSTR1 with EstU1 which is Family VIII carboxylesterase. R1 segment, $\Omega$-loop, and $\beta 8$ - $\beta 9$ hairpin regions are indicated with red, blue, and orange boxes, respectively.

\section{Authors' contributions}

$J H J, S H L, S G K$, and JHL designed and coordinated the study. HSL, JHL, BSK, and CML conducted the experiments. JHJ, SHL, SGK, and JHL wrote the paper, with input and approval from all coauthors. All authors read and approved the final manuscript.

\section{Author details}

${ }^{1}$ Marine Biotechnology Research Division, Korea Institute of Ocean Science and Technology, Ansan 15627, Republic of Korea. ${ }^{2}$ Department of Marine Biotechnology, University of Science and Technology, Daejeon 34113, Republic of Korea. ${ }^{3}$ National Leading Research Laboratory of Drug Resistance 
Proteomics, Department of Biological Sciences, Myongji University, 116 Myongjiro, Yongin, Gyeonggido 17058, Republic of Korea. ${ }^{4}$ Department of Agricultural Biotechnology, National Academy of Agricultural Science, RDA, Jeonju 54875, Republic of Korea.

\section{Acknowledgements}

This work was supported by the KIOST in-house programs (PE99212, PE99263), the Development of Biohydrogen Production Technology Using the Hyperthermophilic Archaea program of the Ministry of Land, Transport and Maritime Affairs, and the research grant from the National Research Lab Program through the National Research Foundation of Korea (NRF) funded by the Ministry of Science, ICT and Future Planning (Grant No. 2011-0027928).

\section{Competing interests}

The authors declare that they have no competing interests.

Received: 10 August 2015 Accepted: 15 April 2016

Published online: 26 April 2016

\section{References}

Altschul SF, Madden TL, Schaffer AA, Zhang J, Zhang Z, Miller W et al (1997) Gapped BLAST and PSI-BLAST: a new generation of protein database search programs. Nucleic Acids Res 25:3389-3402

Arpigny JL, Jaeger KE (1999) Bacterial lipolytic enzymes: classification and properties. Biochem J 343:177-183

Bornscheuer UT (2002) Microbial carboxyl esterases: classification, properties and application in biocatalysis. FEMS Microbiol Rev 26:73-81

Cha SS, An YJ, Jeong CS, Kim MK, Jeon JH, Lee CM et al (2013) Structural basis for the $\beta$-lactamase activity of EstU1, a family VIII carboxylesterase. Proteins 81:2045-2051

De Meester F, Joris B, Reckinger G, Bellefroid-Bourguignon C, Frere JM, Waley SG (1987) Automated analysis of enzyme inactivation phenomena. Application to $\beta$-lactamases and DD-peptidases. Biochem Pharmacol 36:2393-2403

Elend C, Schmeisser C, Leggewie C, Babiak P, Carballeira JD, Steele HL et al (2006) Isolation and biochemical characterization of two novel metagenome-derived esterases. Appl Environ Microbiol 72:3637-3645

Galleni M, Frere JM (1988) A survey of the kinetic parameters of class C B-lactamases. Penicillins. Biochem J 255:119-122

Jeon JH, Kim SJ, Lee HS, Cha SS, Lee JH, Yoon SH et al (2011) Novel metagenome-derived carboxylesterase that hydrolyzes $\beta$-lactam antibiotics. Appl Environ Microbiol 77:7830-7836

Joris B, Ghuysen JM, Dive G, Renard A, Dideberg O, Charlier P et al (1988) The active-site-serine penicillin-recognizing enzymes as members of the Streptomyces R61 DD-peptidase family. Biochem J 250:313-324

Kim JY, Jung HI, An YJ, Lee JH, Kim SJ, Jeong SH et al (2006) Structural basis for the extended substrate spectrum of CMY-10, a plasmid-encoded class $C$ B-lactamase. Mol Microbiol 60:907-916

Kim SJ, Lee CM, Kim MY, Yeo YS, Yoon SH, Kang HC et al (2007) Screening and characterization of an enzyme with $\beta$-glucosidase activity from environmental DNA. J Microbiol Biotechnol 17:905-912

Kim YH, Kwon EJ, Kim SK, Jeong YS, Kim J, Yun HD et al (2010) Molecular cloning and characterization of a novel family VIII alkaline esterase from a compost metagenomic library. Biochem Biophys Res Commun 393:45-49

Knox JR, Moews PC, Frere JM (1996) Molecular evolution of bacterial $\beta$-lactam resistance. Chem Biol 3:937-947

Kuzmic P (1996) Program DYNAFIT for the analysis of enzyme kinetic data: application to HIV proteinase. Anal Biochem 237:260-273

Martin Villacorta J, Arriaga P, Laynez J, Menendez M (1991) Interaction of $\beta$-lactamases I and II from Bacillus cereus with semisynthetic cephamycins. Kinetic studies. Biochem J 279:111-114

Mokoena N, Mathiba K, Tsekoa T, Steenkamp P, Rashamuse K (2013) Functional characterisation of a metagenome derived family VIII esterase with a deacetylation activity on $\beta$-lactam antibiotics. Biochem Biophys Res Commun 437:342-348

Nardini M, Dijkstra BW (1999) a/ $\beta$ hydrolase fold enzymes: the family keeps growing. Curr Opin Struct Biol 9:732-737

Notredame C, Higgins DG, Heringa J (2000) T-Coffee: a novel method for fast and accurate multiple sequence alignment. J Mol Biol 302:205-217

Pehrsson EC, Forsberg KJ, Gibson MK, Ahmadi S, Dantas G (2013) Novel resistance functions uncovered using functional metagenomic investigations of resistance reservoirs. Front Microbiol 4:145

Rashamuse K, Magomani V, Ronneburg T, Brady D (2009) A novel family VIII carboxylesterase derived from a leachate metagenome library exhibits promiscuous $\beta$-lactamase activity on nitrocefin. Appl Microbiol Biotechnol 83:491-500

Saitou N, Nei M (1987) The neighbor-joining method: a new method for reconstructing phylogenetic trees. Mol Biol Evol 4:406-425

Tamura K, Dudley J, Nei M, Kumar S (2007) MEGA4: Molecular Evolutionary Genetics Analysis (MEGA) software version 4.0. Mol Biol Evol 24:1596-1599

Thompson JD, Higgins DG, Gibson TJ (1994) CLUSTAL W: improving the sensitivity of progressive multiple sequence alignment through sequence weighting, position-specific gap penalties and weight matrix choice. Nucleic Acids Res 22:4673-4680

Vercammen K, Garcia-Armisen T, Goeders N, Van Melderen L, Bodilis J, Cornelis P (2013) Identification of a metagenomic gene cluster containing a new class A $\beta$-lactamase and toxin-antitoxin systems. MicrobiologyOpen 2:674-683

Wagner UG, Petersen El, Schwab H, Kratky C (2002) EstB from Burkholderia gladioli: a novel esterase with a $\beta$-lactamase fold reveals steric factors to discriminate between esterolytic and $\beta$-lactam cleaving activity. Protein Sci 11:467-478

Yu EY, Kwon MA, Lee M, Oh JY, Choi JE, Lee JY et al (2011) Isolation and characterization of cold-active family VIII esterases from an arctic soil metagenome. Appl Microbiol Biotechnol 90:573-581

Yun SS, Lee JH, Kim SJ, Kim SS, Park IC, Lee MH et al (2005) Screening and isolation of a gene encoding 4-hydroxyphenylpyruvate dioxygenase from a metagenomics library of soil DNA. J Korean Soc Appl Biol Chem 48:345-351

\section{Submit your manuscript to a SpringerOpen ${ }^{\circ}$ journal and benefit from:}

- Convenient online submission

- Rigorous peer review

- Immediate publication on acceptance

- Open access: articles freely available online

- High visibility within the field

- Retaining the copyright to your article

Submit your next manuscript at $>$ springeropen.com 